\title{
Aspergillus Species and House Dust Mites: Their Allergenicity and Contribution: A Review Article
}

\author{
Ali Mirabi', Masoud Golpour ${ }^{2 *}$, Reza Mirabi ${ }^{1}$ \\ ${ }^{1}$ Student Research Committee, Faculty of Medicine, Mazandaran University of Medical Sciences, Sari, Iran \\ ${ }^{2}$ Department of Dermatology, Faculty of Medicine, Mazandaran University of Medical Sciences, Sari, Iran
}

Corresponding Author: Masoud Golpour, MD, Associate Professor, Department of Dermatology, Faculty of Medicine, Mazandaran University of Medical Sciences, Sari, Iran. Email: golpour1334@yahoo.com

Received March 13, 2018; Accepted May 17, 2018; Online Published June 25, 2018

\begin{abstract}
Allergies are pathological manifestations originating from a trigger-sensitized immune system. Aspergillus species have been reported to be one of the important inhalant allergens in different geographical regions of the world. House dust mite (HDM) allergens play a major role in causing allergic diseases. The emerging literature indicates the allergenicity and contribution of Aspergillus species and HDMs. Allergies erupt when innocuous foreign components are confused as foes by the immune surveillance. The incidence of fungal sensitization in patients with allergic respiratory diseases has been reported from $2.3 \%$ to even $80 \%$ in various studies worldwide. Human skin scales provide food for both mites and fungi. Fungi may either constitute a food supplement for mites or may have an indirect effect by decomposing human dander, thus making it more accessible for HDMs. There is a mutual relationship between fungi and HDMs. In addition to avoid exposure to an allergen as a secondary or tertiary preventive strategy, which is often not sufficiently effective against domestic mites, the treatment of mite allergy is mainly based on allergen-specific immunotherapy (AIT). Treatment with azole antifungal drugs in patients with severe asthma is effective and improves patient quality of life.

Keywords: Allergy, Aspergillus, House Dust Mite, Allergenicity, Dermatophagoides

Citation: Mirabi A, Golpour M, Mirabi R. Aspergillus species and house dust mites: their allergenicity and contribution: a review article. Int J Med Rev. 2018;5(2):55-59. doi:10.29252/IJMR-050203.
\end{abstract}

\section{Introduction}

Allergies are pathological manifestations originating from a trigger-sensitized immune system. Allergies erupt when innocuous foreign components are confused as foes by the immune surveillance. The immune system is a network consisting of lymphoid organs, lymphocytes, and cytokines meant to cordon off against all physical invaders and restore homeostasis. The immune system defends the host against the onslaught of pathogens by its two arms, innate and adaptive immunity. ${ }^{1,2}$ Genetics and the environment are two potent factors that could trigger allergic reactions due to deviations in the immune system. ${ }^{3}$

Allergic diseases of the respiratory system are rapidly becoming global health problems. ${ }^{4-6}$ Thirty percent of the world population suffers from allergies. ${ }^{7}$ The prevalence of respiratory allergy that is clinically expressed by asthma or rhinitis is high and still increasing. The prevalence of asthma in 13-14 year-old children is $14.1 \% .^{8}$ Lifestyle and dietary changes are factors that increase the prevalence of allergic diseases. ${ }^{9}$

Airborne fungi are involved in the etiology of allergic respiratory diseases. ${ }^{10,11}$ Fungal exposure has been recognized as a factor in asthma and other respiratory conditions such as thunderstorm asthma and seasonal epidemic asthma. ${ }^{12,13}$ The incidence of fungal sensitization in patients of allergic respiratory diseases has been reported from $2.3 \%$ to even $80 \%$ in various studies worldwide. ${ }^{14-17}$ Exposure to house dust mite (HDM) allergens in early childhood is a significant factor in determining the subsequent development of asthma. ${ }^{18,19}$ These allergens are not endemic or climate-controlled, but are present in geographically segregated countries like Vietnam, Thailand, Brazil, Italy, and China, to name a few. ${ }^{20-25}$

\begin{abstract}
Allergenicity and the Immune System
The general pathway of allergic responses is based on the role of immunoglobulin E (IgE) and are either immediate or delayed. Allergenicity starts with the recognition of allergens by antigen-presenting cells (APC) like dendritic cells which polarizes Th differentiation towards Th2, causing excess IgE production. The allergens bind to IgE which adheres to the surface of basophils and mast cells and activates them, thus causing cytokine and chemokine secretion, cell degranulation, and the subsequent release of histamines. Released cytokines stimulate other immune cells and mediate inflammation phenomenon. In delayed hypersensitivity, $\mathrm{T}$ lymphocytes, eosinophils, and basophils are recruited to
\end{abstract}

Copyright (C) 2018 The Author(s). This is an open-access article distributed under the terms of the Creative Commons Attribution License (http:// creativecommons.org/licenses/by/4.0), which permits unrestricted use, distribution, and reproduction in any medium, provided the original work is properly cited. 
the site of inflammation. ${ }^{26-30}$ Allergies to HDMs can trigger immune responses and induce IgE-mediated hypersensitivity in predisposed individuals. ${ }^{31,32}$ The higher the severity of the allergic respiratory disease is, the higher the levels of both total IgE and specific sIgE will be..$^{33-35}$

The role of molecular diagnosis in HDM allergy has received little attention in previous studies. The availability of recombinant and natural allergens of Dermatophagoides species makes it possible to investigate the association of the specific molecular profile with clinical manifestations in HDM-allergic individuals. ISAC microarray-based determination of IgE against various Dermatophagoides components may be of value in defining the risk of asthma developing in children. The risk of asthma was twice as high in children with sIgE than in those with Der p2. ${ }^{36,37}$

In 2016, Vidal et al surveyed the association between asthma and sensitization to allergens of Dermatophagoides pteronyssinus. Their study revealed that the concentrations of sIgE to Der-p1 and sIgE to Der-p2 are higher in patients with asthma than in those without it. Reactivity to both Der-p1 and Der-p2 allergens was associated with asthma. ${ }^{38}$ In 2012, Strong et al conducted a study on the application of chitin microparticles on symptoms of allergic hypersensitivity to D. pteronyssinus and Aspergillus fumigatus. Intranasal application of chitin microparticles could reduce serum IgE levels and eosinophilia, airway hyper-responsiveness, and lung inflammation, resulting in the increased release of IL12 , IFN- $\gamma$, and TNF- $\alpha$ cytokines and a reduction in IL-4 cytokine production. Lymphoid tissue stimulation due to the application of chitin microparticles could offer a novel approach for treating allergic diseases in humans. ${ }^{39}$

\section{Aspergillus Species}

Fungi are present everywhere due to an abundant asexual reproduction cycle, through which billions of spores are produced and survive in different environmental conditions. Aspergillosis fumigatus is an important cause of opportunistic infections in humans. Aspergillosis was a much-feared complication of immunosuppressive treatments associated with high mortality and morbidity. ${ }^{40-42}$

Among the different types of fungi, the Aspergillus species have been reported as important inhalant allergens in different geographical regions of the world. ${ }^{14-16,43-52}$ Aspergillus species are the most common causes of invasive mold infections worldwide, especially in immunocompromised patients. $A$. fumigatus is the main etiologic agent of allergic, chronic, and invasive bronchopulmonary fungoides among the infections caused by Aspergillus species. These infections can cause high mortality and morbidity in both immunosuppressed and immunocompetent individuals. ${ }^{53}$ A. fumigatus can causes allergic, acute, and chronic invasive diseases in both humans and animals. ${ }^{54}$

In 1999, Laurent Van Asselt investigated the interactions between domestic mites and fungi. Their study revealed that fungi and mites are two important causes of allergic manifestations such as asthma and rhinitis. Fungi may be a source of food and nutrients for HDMs which provide sterols and vitamins for one of the most important HDMs, D. pteronyssinus. In addition, 2 other mite species also found in the indoor environment, Acarussiro and Tyrophagus putrescentiae, are attracted by fungi and feed on some species of them. ${ }^{55}$

The azole antifungal drugs target lanosterol 14a-demethylase, which is involved in ergosterol biosynthesis. The resulting depletion of ergosterol leads to altered permeability of the fungal membrane and defective fungal cell wall synthesis. ${ }^{56,57}$ Azoles differ from polyenes and echinocandins. Oral treatment with either itraconazole or voriconazole is commonly used in patients with chronic pulmonary aspergillosis. ${ }^{58}$ The survival rates of immunocompromised individuals with invasive aspergillosis have increased significantly due to the availability of azole anti-fungal drugs. This class includes itraconazole, voriconazole, posaconazole (available for clinical use since 1997, 2002, and 2006, respectively), and, most recently, isavuconazole. ${ }^{59}$ These agents have proved beneficial for the treatment of acute and chronic invasive pulmonary aspergillosis, for the prevention of invasive aspergillosis, and for difficult-to-treat diseases such as CNS Aspergillus disease. ${ }^{60,61}$ Triazole antifungal drugs are the basis of treatment for aspergillosis. Azole antifungal agents are recommended for prophylaxis, treatment of acute disease, and long-term maintenance therapy for allergic and chronic aspergillosis. Azole resistance in A. fumigatus has been reported, especially in Europe and Asia, and has resulted in increased treatment failure. ${ }^{62-67}$

In 2013, Mastsuse et al investigated the differential effects of dexamethasone and itraconazole on A. fumigatusexacerbated allergic airway inflammation. Their results showed that $A$. fumigatus infection significantly increased the level of neutrophils and eosinophils in the airway of Dermatophagoides farinae-sensitized mice. Dexamethasone significantly decreased eosinophils; itraconazole significantly decreased both neutrophils and eosinophils in Df-Af mice. Dexamethasone significantly decreased interleukin 5 (IL5), whereas itraconazole significantly reduced MIP-2. Alveolar significantly reduced phagocytotic activity of A. fumigatus. Thus, a combination of dexamethasone and itraconazole might be effective for the management of fungus-exacerbated asthma. ${ }^{68}$

\section{House Dust Mites}

HDMs are indoor allergens. It is difficult to get rid of these pesky allergens which occur in nooks and crannies of houses and heighten the risk of asthma, dermatitis, sinusitis, rhinitis, otitis and other allergic or inflammatory diseases. ${ }^{69}$ Seventyfive percent of the mites' body weight is composed of water. They are not able to drink water; they absorb water through their legs from the humidity in the environment. They absorb water at a relative humidity of at least $65 \%$ and lose water through evaporation at approximately $55^{\circ} \mathrm{C}$. Their survival rate decreases at humidity below 50\%. HDMs are poikilothermic. They have optimal proliferation at 75\%-80\% humidity and $25-30^{\circ} \mathrm{C}$. On the other hand, they are able to survive large fluctuations in humidity and temperature by 
burrowing themselves into areas where moisture can be better retained, such as in mattresses, carpets, or sofas. Hence, it may take months of low humidity for HDMs to die and longer for their allergens to dissipate. ${ }^{70-72}$ Approximately all body parts of mites are allergens which can trigger allergy in $85 \%$ of asthmatic individuals. ${ }^{73}$

More than twenty types of HDM allergens have been identified. ${ }^{74}$ One of the most common groups of indoor allergens causing allergic rhinitis or allergic asthma is found in the bodies and feces of HDMs, with the two main species being $D$. pteronyssinus and D. farina. ${ }^{75-77}$ Recently, $\alpha$-actinin was recognized as a new type of HDM allergen. ${ }^{78}$ These allergens have been identified not only in houses but also in schools, which can jeopardize the children's health and make them susceptible to health-related consequences. ${ }^{79}$

In 1987, de Saint Georges-Gridelet conducted a study on the vitamin requirements of $D$. pteronyssinus with its fungal association. Their investigation showed that additional B vitamins greatly enhanced the growth of $D$. pteronyssinus in the floor-dust habitat. Mite growth in the presence of added vitamin D was also greater in floor dust than in mattress dust. The differential effects of additional vitamins, depending on the substrate, confirmed the importance of fungal intervention in the diet of the mite.

In conclusion, the importance of certain factors such as diet on the ecology of the house-dust mite in relation to endemic fungi has been shown. Fungal activity in the natural substrate of $D$. pteronyssinus should furnish the needed vitamins B and $\mathrm{D}$ for the growth and development of this mite. Related to the sufficiency of these growth factors for mites in mattress dust as well as the greater growth of the endemic fungi on that substrate, this knowledge clearly defines the true biotope of D. pteronyssinus. ${ }^{80}$

In addition to avoiding exposure to allergens as a secondary or tertiary preventive strategy, which is often not sufficiently effective against domestic mites, the treatment of mite allergy is based mainly on anti-allergic pharmacotherapy as well as on allergen-specific immunotherapy (AIT). ${ }^{77,81-83}$

The World Health Organization (WHO) highlighted the clinical efficacy of AIT in patients with HDM-induced allergic rhinitis and allergic asthma. ${ }^{84} \mathrm{~A}$ large number of metaanalyses have stated the clinical efficacy of both subcutaneous and sublingual AIT (SCIT and SLIT) in HDM allergy. ${ }^{77,85-87}$ There are challenges on the efficacy of allergen avoidance as a therapeutic approach. Acaricide chemicals are effective in eliminating mites, but unfortunately, they have short-duration effectiveness, and there is concern about the safety of their use in homes. Physical interventions such as beds impermeable to domestic mites, regular use of vacuum cleaners, heating, freezing, and drying the equipment are suggested. However, no study has found any significant clinical benefit with these interventions. $^{70,88-90}$

\section{Conclusions}

Frequent exposure to allergens can lead to allergic manifestations including asthma, rhinitis, atopic dermatitis, sinusitis, urticaria, and conjunctivitis in susceptible individuals. ${ }^{74} \mathrm{HDM}$ allergens are not limited to low-income and rural areas in developing countries; they are present in urban areas as well. ${ }^{20,21}$ Avoidance of allergens is widely recommended to diminish the severity of allergic rhinitis or allergic asthma symptoms in susceptible individuals. Moreover, a comprehensive approach such as avoiding smoking, improving training and education, and regular assessments may be effective..$^{91,92}$

\section{Authors' Contributions}

AM study conception and design, acquisition of data, drafting of the manuscript and revision of the article; MG conception and design of the study, critical revision of the article and final approval of the version to be published; RM substantial contributions to study design, acquisition of data and cowrote the paper.

\section{Conflict of Interest Disclosures}

The authors declare they have no conflicts of interest.

\section{References}

1. Baird FJ, Lopata AL. The dichotomy of pathogens and allergens in vaccination approaches. Front Microbiol. 2014;5:365. doi:10.3389/ fmicb.2014.00365.

2. Parkin J, Cohen B. An overview of the immune system. Lancet. 2001;357(9270):1777-1789. doi:10.1016/s0140-6736(00)049047 .

3. Parronchi P, Brugnolo F, Sampognaro S, Maggi E. Genetic and environmental factors contributing to the onset of allergic disorders. Int Arch Allergy Immunol. 2000;121(1):2-9. doi:10.1159/000024291.

4. Sheffer A, Bartal M, Bousquet J. Global strategy for asthma management and prevention. WHO Workshop Report Publication; 1995.

5. Bousquet J, Khaltaev N, Cruz AA, et al. Allergic Rhinitis and its Impact on Asthma (ARIA) 2008 update (in collaboration with the World Health Organization, GA(2)LEN and AllerGen). Allergy. 2008;63 Suppl 86:8-160. doi:10.1111/j.1398-9995.2007.01620.x.

6. Koppelman GH. Gene-environment interaction in allergic disease: more questions, more answers? J Allergy Clin Immunol. 2007;120(6):1266-1268. doi:10.1016/j.jaci.2007.10.007.

7. Dave ND, Xiang L, Rehm KE, Marshall GD Jr. Stress and allergic diseases. Immunol Allergy Clin North Am. 2011;31(1):55-68. doi:10.1016/j.iac.2010.09.009.

8. Mallol J, Crane J, von Mutius E, Odhiambo J, Keil U, Stewart A. The International Study of Asthma and Allergies in Childhood (ISAAC) Phase Three: a global synthesis. Allergol Immunopathol (Madr). 2013;41(2):73-85. doi:10.1016/j.aller.2012.03.001.

9. Huang SK, Zhang Q, Qiu Z, Chung KF. Mechanistic impact of outdoor air pollution on asthma and allergic diseases. J Thorac Dis. 2015;7(1):23-33. doi:10.3978/j.issn.2072-1439.2014.12.13.

10. Simon-Nobbe B, Denk U, PollV, Rid R, Breitenbach M. The spectrum of fungal allergy. Int Arch Allergy Immunol. 2008;145(1):58-86. doi:10.1159/000107578.

11. Zureik M, Neukirch C, Leynaert B, Liard R, Bousquet J, Neukirch F. Sensitisation to airborne moulds and severity of asthma: cross sectional study from European Community respiratory health survey. BMJ. 2002;325(7361):411-414. doi:10.1136/bmj.325.7361.411.

12. Platts-Mills TA, Hayden ML, Chapman MD, Wilkins SR. Seasonal variation in dust mite and grass-pollen allergens in dust from the houses of patients with asthma. J Allergy Clin Immunol. 1987;79(5):781-791. doi:10.1016/0091-6749(87)90211-9.

13. van der Heide S, de Monchy JG, de Vries K, Bruggink TM, Kauffman HF. Seasonal variation in airway hyperresponsiveness and natural exposure to house dust mite allergens in patients with asthma. J Allergy Clin Immunol. 1994;93(2):470-475. doi:10.1016/00916749(94)90356-5

14. Ezeamuzie $\mathrm{Cl}$, Al-Ali S, Khan M, et al. IgE-mediated sensitization to 
mould allergens among patients with allergic respiratory diseases in a desert environment. Int Arch Allergy Immunol. 2000;121(4):300307. doi:10.1159/000024343.

15. Mari A, Schneider P, Wally V, Breitenbach M, Simon-Nobbe B. Sensitization to fungi: epidemiology, comparative skin tests, and lgE reactivity of fungal extracts. Clin Exp Allergy. 2003;33(10):14291438. doi:10.1046/j.1365-2222.2003.01783.x.

16. Gioulekas D, Damialis A, Papakosta D, Spieksma F, Giouleka $\mathrm{P}$, Patakas D. Allergenic fungi spore records (15 years) and sensitization in patients with respiratory allergy in ThessalonikiGreece. J Investig Allergol Clin Immunol. 2004;14(3):225-231.

17. D'Amato G, Chatzigeorgiou G, Corsico R, et al. Evaluation of the prevalence of skin prick test positivity to Alternaria and Cladosporium in patients with suspected respiratory allergy. A European multicenter study promoted by the Subcommittee on Aerobiology and Environmental Aspects of Inhalant Allergens of the European Academy of Allergology and Clinical Immunology. Allergy. 1997;52(7):711-716. doi:10.1111/j.1398-9995.1997. tb01227.x.

18. Sporik R, Holgate ST, Platts-Mills TA, Cogswell JJ. Exposure to house-dust mite allergen (Der $\mathrm{p} \mathrm{I}$ ) and the development of asthma in childhood. A prospective study. N Engl J Med. 1990;323(8):502507. doi:10.1056/nejm199008233230802.

19. Sears MR, Herbison GP, Holdaway MD, Hewitt CJ, Flannery EM, Silva PA. The relative risks of sensitivity to grass pollen, house dust mite and cat dander in the development of childhood asthma. Clin Exp Allergy. 1989;19(4):419-424. doi:10.1111/j.1365-2222.1989. tb02408.x.

20. Lam HT, Ekerljung L, Bjerg A, Van TTN, Lundback B, Ronmark E. Sensitization to airborne allergens among adults and its impact on allergic symptoms: a population survey in northern Vietnam. Clin Transl Allergy. 2014;4(1):6. doi:10.1186/2045-7022-4-6.

21. Macan J, Plavec D, Kanceljak B, Milkovic-Kraus S. Exposure levels and skin reactivity to German cockroach (Blattella germanica) in Croatia. Croat Med J. 2003;44(6):756-760.

22. Tungtrongchitr A, Sookrung N, Munkong N, et al. The levels of cockroach allergen in relation to cockroach species and allergic diseases in Thai patients. Asian Pac J Allergy Immunol. 2004;22(23):115-121.

23. Tobias KR, Ferriani VP, Chapman MD, Arruda LK. Exposure to indoor allergens in homes of patients with asthma and/or rhinitis in southeast Brazil: effect of mattress and pillow covers on mite allergen levels. Int Arch Allergy Immunol. 2004;133(4):365-370. doi:10.1159/000077356.

24. Liccardi G, Baldi G, Ciccarelli A, et al. Sensitization to cockroach allergens in the urban atopic populations living in Campania district (southern Italy). A multicenter study. Eur Ann Allergy Clin Immunol. 2014;46(1):12-16.

25. Sun BQ, Lai XX, Gjesing B, Spangfort MD, Zhong NS. Prevalence of sensitivity to cockroach allergens and IgE cross-reactivity between cockroach and house dust mite allergens in Chinese patients with allergic rhinitis and asthma. Chin Med J (Engl). 2010;123(24):35403544. doi:10.3760/cma.j.issn.0366-6999.2010.24.007.

26. Salazar F, Ghaemmaghami AM. Allergen recognition by innate immune cells: critical role of dendritic and epithelial cells. Front Immunol. 2013;4:356. doi:10.3389/fimmu.2013.00356.

27. Galli SJ, Tsai M. IgE and mast cells in allergic disease. Nat Med. 2012;18(5):693-704. doi:10.1038/nm.2755.

28. Stone KD, Prussin C, Metcalfe DD. IgE, mast cells, basophils, and eosinophils. J Allergy Clin Immunol. 2010;125(2 Suppl 2):S73-80. doi:10.1016/j.jaci.2009.11.017.

29. Saggini A, Maccauro G, Tripodi D, et al. Allergic inflammation: role of cytokines with special emphasis on IL-4. Int J Immunopathol Pharmacol. 2011;24(2):305-311. doi:10.1177/039463201102400204.

30. Janeway CA Jr, Travers P, Walport M, Shlomchik MJ. Immunobiology: The Immune System in Health and Disease. 5th ed. New York: Garland Science; 2001:12-3.

31. Arlian LG. Arthropod allergens and human health. Annu Rev Entomol. 2002;47:395-433. doi:10.1146/annurev. ento.47.091201.145224.

32. Kim CW, Hong CS. Allergy to miscellaneous household arthropods. Protein Pept Lett. 2007;14(10):982-991. doi:10.2174/092986607782541079.

33. Davila I, Valero A, Entrenas LM, Valveny N, Herraez L. Relationship between serum total IgE and disease severity in patients with allergic asthma in Spain. J Investig Allergol Clin Immunol. 2015;25(2):120127.

34. Custovic A, Simpson A. The role of inhalant allergens in allergic airways disease. J Investig Allergol Clin Immunol. 2012;22(6):393401; qiuz follow 401.

35. Erwin EA, Ronmark E, Wickens K, et al. Contribution of dust mite and cat specific IgE to total IgE: relevance to asthma prevalence. J Allergy Clin Immunol. 2007;119(2):359-365. doi:10.1016/j. jaci.2006.12.648.

36. Custovic A, Sonntag HJ, Buchan IE, Belgrave D, Simpson A, Prosperi MCF. Evolution pathways of IgE responses to grass and mite allergens throughout childhood. J Allergy Clin Immunol. 2015;136(6):1645-1652.e1648. doi:10.1016/j.jaci.2015.03.041.

37. Resch $Y$, Michel S, Kabesch M, Lupinek C, Valenta R, Vrtala S. Different IgE recognition of mite allergen components in asthmatic and nonasthmatic children. J Allergy Clin Immunol. 2015;136(4):1083-1091. doi:10.1016/j.jaci.2015.03.024.

38. Vidal C, Lojo S, Juangorena M, Gonzalez-Quintela A. Association between asthma and sensitization to allergens of Dermatophagoides pteronyssinus. J Investig Allergol Clin Immunol. 2016;26(5):304309. doi:10.18176/jiaci.0048.

39. Strong P, Clark H, Reid K. Intranasal application of chitin microparticles down-regulates symptoms of allergic hypersensitivity to Dermatophagoides pteronyssinus and Aspergillus fumigatus in murine models of allergy. Clin Exp Allergy. 2002;32(12):17941800. doi:10.1046/j.1365-2222.2002.01551.x.

40. Patterson TF, Kirkpatrick WR, White M, et al. Invasive aspergillosis. Disease spectrum, treatment practices, and outcomes. 13 Aspergillus Study Group. Medicine (Baltimore). 2000;79(4):250260. doi:10.1097/00005792-200007000-00006.

41. Denning DW, Stevens DA. Antifungal and surgical treatment of invasive aspergillosis: review of 2,121 published cases. Rev Infect Dis. 1990;12(6):1147-1201. doi:10.1093/clinids/12.6.1147.

42. Lin SJ, Schranz J, Teutsch SM. Aspergillosis case-fatality rate: systematic review of the literature. Clin Infect Dis. 2001;32(3):358366. doi:10.1086/318483.

43. Fang Z, Ouyang Z, Hu L, Wang X, Zheng H, Lin X. Culturable airborne fungi in outdoor environments in Beijing, China. Sci Total Environ. 2005;350(1-3):47-58.doi:10.1016/j.scitotenv.2005.01.032.

44. Segvic Klaric M, Pepeljnjak S. A year-round aeromycological study in Zagreb area, Croatia. Ann Agric Environ Med. 2006;13(1):55-64.

45. Wu YH, Chan CC, Rao CY, et al. Characteristics, determinants, and spatial variations of ambient fungal levels in the subtropical Taipei metropolis. Atmos Environ. 2007;41(12):2500-2509. doi:10.1016/j. atmosenv.2006.11.035.

46. O'Gorman CM, Fuller HT. Prevalence of culturable airborne spores of selected allergenic and pathogenic fungi in outdoor air. Atmos Environ. 2008;42(18):4355-4368. doi:10.1016/j. atmosenv.2008.01.009.

47. Sharma D, Dutta BK, Singh AB, Shome BR. Aerobiological, biochemical and immunological studies on some of the dominant Aspergillus species of South Assam (India). Aerobiologia. 2007;23(3):201. doi:10.1007/s10453-007-9064-0.

48. Crameri R, Garbani M, Rhyner C, Huitema C. Fungi: the neglected allergenic sources. Allergy. 2014;69(2):176-185. doi:10.1111/ all.12325.

49. Aggarwal S, Chhabra SK, Saxena RK, Agarwal MK. Heterogeneity of immune responses to various Aspergillus species in patients with allergic respiratory diseases. Indian J Chest Dis Allied Sci. 2000;42(4):249-258.

50. Horner WE, Helbling A, Salvaggio JE, Lehrer SB. Fungal allergens. Clin Microbiol Rev. 1995;8(2):161-179. doi:10.1128/cmr.8.2.161.

51. Kurup VP, Banerjee B. Fungal allergens and peptide epitopes. Peptides. 2000;21(4):589-599. doi:10.1016/S0196$9781(00) 00181-9$.

52. Crameri R, Zeller S, Glaser AG, Vilhelmsson M, Rhyner C. Cross-reactivity among fungal allergens: a clinically relevant phenomenon? Mycoses. 2009;52(2):99-106. doi:10.1111/j.1439- 
0507.2008.01644.x.

53. Denning DW, Pleuvry A, Cole DC. Global burden of allergic bronchopulmonary aspergillosis with asthma and its complication chronic pulmonary aspergillosis in adults. Med Mycol. 2013;51(4):361-370. doi:10.3109/13693786.2012.738312.

54. Kosmidis C, Denning DW. The clinical spectrum of pulmonary aspergillosis. Thorax. 2015;70(3):270-277. doi:10.1136/ thoraxjnl-2014-206291.

55. Van Asselt L. Interactions between domestic mites and fungi. Indoor Built Environ. 1999;8(4):216-220. doi:10.1159/000024644.

56. Shapiro RS, Robbins N, Cowen LE. Regulatory circuitry governing fungal development, drug resistance, and disease. Microbiol Mol Biol Rev. 2011;75(2):213-267. doi:10.1128/mmbr.00045-10.

57. Odds FC, Brown AJ, Gow NA. Antifungal agents: mechanisms of action. Trends Microbiol. 2003;11(6):272-279. doi:10.1016/ S0966-842X(03)00117-3.

58. Al-Shair K, Atherton GT, Harris C, Ratcliffe L, Newton PJ, Denning DW. Long-term antifungal treatment improves health status in patients with chronic pulmonary aspergillosis: a longitudinal analysis. Clin Infect Dis. 2013;57(6):828-835. doi:10.1093/cid/ cit411.

59. Miceli MH, Kauffman CA. Isavuconazole: a new broad-spectrum triazole antifungal agent. Clin Infect Dis. 2015;61(10):1558-1565. doi:10.1093/cid/civ571.

60. Walsh TJ, Anaissie EJ, Denning DW, et al. Treatment of aspergillosis: clinical practice guidelines of the Infectious Diseases Society of America. Clin Infect Dis. 2008;46(3):327-360. doi:10.1086/525258.

61. Schwartz S, Ruhnke M, Ribaud P, et al. Improved outcome in central nervous system aspergillosis, using voriconazole treatment. Blood. 2005;106(8):2641-2645. doi:10.1182/blood-2005-02-0733.

62. Verweij PE, Mellado E, Melchers WJ. Multiple-triazole-resistant aspergillosis. N Engl J Med. 2007;356(14):1481-1483. doi:10.1056/ NEJMc061720.

63. van der Linden JW, Snelders E, Kampinga GA, et al. Clinical implications of azole resistance in Aspergillus fumigatus, The Netherlands, 2007-2009. Emerg Infect Dis. 2011;17(10):18461854. doi:10.3201/eid1710.110226.

64. Howard SJ, Cerar D, Anderson MJ, et al. Frequency and evolution of Azole resistance in Aspergillus fumigatus associated with treatment failure. Emerg Infect Dis. 2009;15(7):1068-1076. doi:10.3201/ eid1507.090043.

65. Arendrup MC, Mavridou E, Mortensen KL, et al. Development of azole resistance in Aspergillus fumigatus during azole therapy associated with change in virulence. PLoS One. 2010;5(4):e10080. doi:10.1371/journal.pone.0010080.

66. Chowdhary A, Kathuria S, Randhawa HS, Gaur SN, Klaassen $\mathrm{CH}$, Meis JF. Isolation of multiple-triazole-resistant Aspergillus fumigatus strains carrying the TR/L98H mutations in the cyp51A gene in India. J Antimicrob Chemother. 2012;67(2):362-366. doi:10.1093/ $\mathrm{jac} / \mathrm{dkr} 443$.

67. Lockhart SR, Frade JP, Etienne KA, Pfaller MA, Diekema DJ, Balajee SA. Azole resistance in Aspergillus fumigatus isolates from the ARTEMIS global surveillance study is primarily due to the TR/ L98H mutation in the cyp51A gene. Antimicrob Agents Chemother. 2011;55(9):4465-4468. doi:10.1128/aac.00185-11.

68. Matsuse H, Fukushima C, Fukahori S, et al. Differential effects of dexamethasone and itraconazole on Aspergillus fumigatusexacerbated allergic airway inflammation in a murine model of mite-sensitized asthma. Respiration. 2013;85(5):429-435. doi:10.1159/000345861.

69. Arshad SH. Does exposure to indoor allergens contribute to the development of asthma and allergy? Curr Allergy Asthma Rep. 2010;10(1):49-55. doi:10.1007/s11882-009-0082-6.

70. Portnoy J, Chew GL, Phipatanakul W, et al. Environmental assessment and exposure reduction of cockroaches: a practice parameter. J Allergy Clin Immunol. 2013;132(4):802-808.e801825. doi:10.1016/j.jaci.2013.04.061.

71. New TR. Matthew J. Colloff: Dust mites. J Insect Conserv. 2009;13(6):677-8. doi:10.1007/s10841-009-9234-1.

72. Adkinson NF Jr, Bochner BS, Burks AW, et al. Middleton's allergy: principles and practice. Elsevier Health Sciences; 2013.

73. Gregory LG, Lloyd CM. Orchestrating house dust mite-associated allergy in the lung. Trends Immunol. 2011;32(9):402-411. doi:10.1016/j.it.2011.06.006.

74. Baxi SN, Phipatanakul W. The role of allergen exposure and avoidance in asthma. Adolesc Med State Art Rev. 2010;21(1):5771, viii-ix.

75. Mosbech H. House dust mite allergy. Allergy. 1985;40(2):81-91. doi:10.1111/j.1398-9995.1985.tb02665.x.

76. Brozek JL, Bousquet J, Baena-Cagnani CE, et al. Allergic Rhinitis and its Impact on Asthma (ARIA) guidelines: 2010 revision. J Allergy Clin Immunol. 2010;126(3):466-476. doi:10.1016/j. jaci.2010.06.047.

77. Calderon MA, Casale TB, Nelson HS, Demoly P. An evidencebased analysis of house dust mite allergen immunotherapy: a call for more rigorous clinical studies. J Allergy Clin Immunol. 2013;132(6):1322-1336. doi:10.1016/j.jaci.2013.09.004.

78. An S, Shen C, Liu X, et al. Alpha-actinin is a new type of house dust mite allergen. PLoS One. 2013;8(12):e81377. doi:10.1371/journal. pone.0081377.

79. Abramson SL, Turner-Henson A, Anderson L, et al. Allergens in school settings: results of environmental assessments in 3 city school systems. J Sch Health. 2006;76(6):246-249. doi:10.1111/ j.1746-1561.2006.00105.x.

80. de Saint Georges-Gridelet D. Vitamin requirements of the European house dust mite, Dermatophagoides pteronyssinus (Acari: Pyroglyphidae), in relation to its fungal association. J Med Entomol. 1987;24(4):408-411. doi:10.1093/jmedent/24.4.408.

81. Custovic A, Wijk RG. The effectiveness of measures to change the indoor environment in the treatment of allergic rhinitis and asthma: ARIA update (in collaboration with GA(2)LEN). Allergy. 2005;60(9):1112-1115. doi:10.1111/j.1398-9995.2005.00934.x.

82. Nelson HS. Update on house dust mite immunotherapy: are more studies needed? Curr Opin Allergy Clin Immunol. 2014;14(6):542548. doi:10.1097/aci.0000000000000104.

83. Calderon MA, Demoly P, Gerth van Wijk R, et al. EAACl: A European Declaration on Immunotherapy. Designing the future of allergen specific immunotherapy. Clin Transl Allergy. 2012;2(1):20. doi:10.1186/2045-7022-2-20.

84. Bousquet J, Lockey R, Malling HJ. Allergen immunotherapy: therapeutic vaccines for allergic diseases. A WHO position paper. J Allergy Clin Immunol. 1998;102(4 Pt 1):558-562. doi:10.1016/ S0091-6749(98)70271-4.

85. Abramson MJ, Puy RM, Weiner JM. Injection allergen immunotherapy for asthma. Cochrane Database Syst Rev. 2010(8):Cd001186. doi:10.1002/14651858.CD001186.pub2.

86. Compalati E, Passalacqua G, Bonini M, Canonica GW. The efficacy of sublingual immunotherapy for house dust mites respiratory allergy: results of a GA2LEN meta-analysis. Allergy. 2009;64(11):1570-1579. doi:10.1111/j.1398-9995.2009.02129.x.

87. Eifan AO, Calderon MA, Durham SR. Allergen immunotherapy for house dust mite: clinical efficacy and immunological mechanisms in allergic rhinitis and asthma. Expert Opin Biol Ther. 2013;13(11):1543-1556. doi:10.1517/14712598.2013.844226.

88. Larenas-Linnemann $\mathrm{D}$, Michels $\mathrm{A}$, Dinger $\mathrm{H}$, et al. Allergen sensitization linked to climate and age, not to intermittent-persistent rhinitis in a cross-sectional cohort study in the (sub)tropics. Clin Transl Allergy. 2014;4:20. doi:10.1186/2045-7022-4-20.

89. Nurmatov U, van Schayck CP, Hurwitz B, Sheikh A. House dust mite avoidance measures for perennial allergic rhinitis: an updated Cochrane systematic review. Allergy. 2012;67(2):158-165. doi:10.1111/j.1398-9995.2011.02752.x.

90. Wright LS, Phipatanakul W. Environmental remediation in the treatment of allergy and asthma: latest updates. Curr Allergy Asthma Rep. 2014;14(3):419. doi:10.1007/s11882-014-0419-7.

91. Morgan WJ, Crain EF, Gruchalla RS, et al. Results of a homebased environmental intervention among urban children with asthma. N Engl J Med. 2004;351(11):1068-1080. doi:10.1056/ NEJMoa032097.

92. Krieger J, Jacobs DE, Ashley PJ, et al. Housing interventions and control of asthma-related indoor biologic agents: a review of the evidence. J Public Health Manag Pract. 2010;16(5 Suppl):S11-20. doi:10.1097/PHH.0b013e3181ddcbd9. 